\title{
Expression and antisense inhibition of transgenes in Phytophthora infestans is modulated by choice of promoter and position effects
}

(Oomycetes; transformation, fungi; $\beta$-glucuronidase; $\beta$-galactosidase; late blight)

\author{
Howard S. Judelson ${ }^{\mathrm{a}}$, Robert Dudler ${ }^{\mathrm{b}}$, Corné M.J. Pieterse ${ }^{\mathrm{c}, *}$, Shiela E. Unkles ${ }^{\mathrm{d}, *}$ and \\ Richard W. Michelmore \\ ${ }^{a}$ Center for Engineering Plants for Resistance Against Pathogens, and ${ }^{\mathrm{e} D e p a r t m e n t ~ o f ~ V e g e t a b l e ~ C r o p s, ~ U n i v e r s i t y ~ o f ~ C a l i f o r n i a, ~ D a v i s . ~ C A ~ 95616, ~ U S A ; ~}$ \\ ${ }^{\mathrm{b}}$ Institute for Plant Biology, University of Zürich, CH-8008 Zürich. Switzerland. Tel. (41-1) 85-4211; ' Department of Phytopathology, Wageningen \\ Agricultural University, 6700 EE Wageningen, The Netherlands. Tel. (31-8370) 83130; and ' Plant Molecular Genetics Unit, University of St. Andrews, \\ Fife KY16 9TH, United Kingdom. Tel. (44-334) 76161
}

Received by G.P. Livi: 7 December 1992; Accepted: 11 May 1993; Received at publishers: 17 June 1993

\section{SUMMARY}

Procedures were identified for manipulating the expression of genes in the oomycete fungus, Phytophthora infestans. The activities of five putative promoter sequences, derived from the $5^{\prime}$ regions of oomycete genes, were measured in transient assays performed in protoplasts and in stable transformants. The sequences tested were from the ham 34 and hsp70 genes of Bremia lactucae, the actin-encoding genes of P. infestans and P. megasperma, and a polyubiquitin-encoding gene of $P$. infes ans. Experiments using the GUS reporter gene (encoding $\beta$-glucul onidase) demonstrated that each $5^{\prime}$ fragment had promoter activity, but that their activities varied over a greater than tenfold range. Major variation was revealed in the level of transgene expression in individual transformants containing the same promoter::GUS or promoter::lac $Z$ fusion. The level of expression was not simply related to the number of genes present, suggesting that position effects were also influencing expression. Fusions between the ham 34 promoter, and full-length and partial GUS genes in the antisense orientation blocked the expression of GUS in protoplasts and in stable transformants.

\section{INTRODUCTION}

The oomycete fungus, Phytophthora infestans, causes late blight on potato, tomato, and several other Solanaceous plants. Procedures for introducing genes and manipulating their expression are required for molecular genetic studies of $P$. infestans. The development of

Correspondence to: Dr. H.S. Judelson, CEPRAP, University of California, Davis, CA 95616, USA. Tel. (1-916) 757-3256; Fax (1-916) 753-2697.

${ }^{*}$ Current addresses: (C.M.J.P.) Department of Plant Ecology and Evolutionary Biology, Utrecht University, P.O. Box 800-84, 3508 TB Utrecht, The Netherlands. Tel. (31-30) 536700; (S.E.U.) Scottish Crop Research Institute, Invergowrie, Scotland DD2 5DA, United Kingdom. Tel. (44-382) 562731.

Abbreviations: act, actin-encoding gene of $P$. megasperma; act $A$, actinencoding gene of $P$. infestans; $\beta$ Gal, $\beta$-galactosidase; $B$., Bremia; bp, base these methods has progressed more slowly for oomycetes than for the higher fungi (i.e., ascomycetes and basidiomycetes), in part due to the lack of suitable promoters. Although frequently considered as fungi due to their generally filamentous growth habit, the oomycetes have poor taxonomic affinity with the higher fungi, based on studies of cell wall composition (Bartnicki-Garcia, 1968), steroid

pair(s); E., Escherichia; G418, Geneticin; GUS, $\beta$-glucuronidase; GUS, GUS-encoding gene of E. coli; ham34, gene encoding Ham34 of $B$. lactucae; hpt, gene encoding Hy phosphotransferase; hsp 70, gene encoding $\mathrm{Hsp} 70$ of $B$. lactucae; Hy, hygromycin $\mathrm{B} ; \mathbf{k b}$, kilobase(s) or $1000 \mathrm{bp} ; \quad n p t I I$, gene encoding neomycin phosphotransferase; nt, nucleotides(s); ORF, open reading frame; $P$., Phytophthora; PCR, polymerase chain reaction; Pollk, Klenow (large) fragment of E. coli DNA polymerase I; ${ }^{\mathbf{R}}$, resistant/resistance; SDS, sodium dodecyl sulfate; SSC, $0.15 \mathrm{M} \mathrm{NaCl} / 0.015 \mathrm{M} \mathrm{Na}$.citrate $\mathrm{pH} \mathrm{7.6;} \mathrm{ubi} 3 R$, ubiquitin-encoding gene of $P$. infestans; :., novel junction (fusion or insertion). 
metabolism (Warner et al., 1983), and rRNA sequence (Förster et al., 1991). Promoters from genes of nonoomycetes, including ascomycete and basidiomycete fungi, displayed no activity in transient expression assays in several species of oomycetes, while oomycete promoters (from Bremia lactucae) were active (Judelson et al., 1992). Fusion of the B. lactucae promoters to genes for drug resistance enabled the isolation of stable transformants of $P$. infestans and $P$. megasperma f. sp. glycinea; analysis of marker gene transcripts confirmed the recognition of the B. lactucae promoters (Judelson et al., 1991; 1993).

The goal of this study was to expand the technologies for manipulating gene expression in P. infestans. The expression of GUS and lacZ, and the inhibition of GUS expression using antisense sequences, were characterized in stable transformants and in transient assays using promoters derived from five genes of oomycetes. A subset of these promoters had previously been tested using GUS in transient assays only (Judelson et al., 1992). These data will be crucial to our future studies, in which we will manipulate genes important to the pathogenicity, hostcultivar specificity, and growth of $P$. infestans.

\section{RESULTS AND DISCUSSION}

\section{(a) Comparison of promoters in transient assays}

Presumed transcriptional regulatory sequences from the upstream regions of five oomycete genes were tested for their abilities to express the GUS marker gene in protoplasts of $P$. infestans. For convenience, these sequences are referred to as 'promoters', i.e., fragments of DNA determining the initiation of transcription, although other regulators of expression such as enhancers or silencers might be present (Johnson and McKnight, 1989). The promoters were from the ham 34 gene of B. lactucae, which encodes a highly expressed, putative structural protein (Judelson and Michelmore, 1990); a hsp70 gene of B. lactucae (Judelson and Michelmore, 1989); actinencoding genes of $P$. megasperma and P. infestans (Dudler, 1990; Unkles et al., 1991), and a polyubiquitin-encoding gene of $P$. infestans (Pieterse et al., 1991). GUS expression vectors varying only in their promoter sequences (Table I) were introduced into protoplasts, and GUS activity was determined after an overnight incubation (Table II). Each construct enabled the expression of the marker gene, but up to tenfold differences in the apparent activities of the promoters were observed (Table II).

Since the $5^{\prime}$ regions tested as promoters ranged from 400 to $1000 \mathrm{bp}$, it was possible that the larger and more active fragments (such as the 920 -bp promoter fragment ir. pHAMT35G) might contain transcriptional enhancers not present in the smaller elements. However, this was not supported by separate experiments with pDHAMT35G, which contained a truncated (400 bp) ham 34 promoter. The levels of transient GUS activity obtained using pDHAMT $35 \mathrm{G}$ were $93 \pm 12 \%$ of that obtained with pHAMT35G.

\section{(b) Comparison of promoters in stable transformants}

The relative activities of each promoter were tested in stable transformants obtained by cotransformation of the GUS plasmids with the G418 ${ }^{\mathrm{R}}$ plasmid, pTH209. Approximately $80 \%$ of the resulting drug-resistant colonies stained positively for GUS activity in histochemical assays. Variation in the intensity of staining was observed, both between colonies transformed with different GUS plasmids and those with the same plasmid.

Quantitative measurements of GUS in transformants revealed considerable variation in activity between the promoters, as well as between individuals containing the same promoter-GUS fusion (Fig. 1, top). For each promoter tested, the specific activity of GUS was determined in vegetative mycelia from 20 transformants randomly selected from among the histochemically-staining colonies. Although most transformants were not examined in Southern blots, it is likely that the plasmids had integrated at different genomic sites in different transformants since homologous recombination has not been observed during $P$ infestans transformation. The average relative activities for each promoter in the stable transformants did not precisely parallel the ranking observed in the transient assays. For example, the average activity of the ham 34 promoter increased relative to the other promoters. This may reflect differences in the binding of regulatory proteins to newly introduced vs. stably integrated DNA, possibly related to the organization of chromatin. Alternatively, in a transient assay possible negative regulators may have been titrated by the large number of introduced molecules of DNA. Also, the $h s p 70$ promoter may have been induced to a higher level by factors produced in response to stresses associated with protoplasting in the transient assay, as reported in plants (Ainley and Key, 1990).

Major differences in expression among individual transformants were demonstrated for each promoter. To test if this was unique to GUS, cotransformants expressing $\beta$ Gal were obtained using pHAMT35L (lacZ) and pTH209 $\left(\mathrm{G} 418^{\mathrm{R}}\right)$. The variation in $\beta \mathrm{Gal}$ activity in 15 randomly selected cotransformants (Fig. 1, bottom) was similar to that of GUS. Several observations suggested that this could be attributed to chromosomal position effects. No straightforward relationship was revealed between GUS activity (in pHAMT35G cotransformants) 
TABLE I

Vectors used in this studya

\begin{tabular}{llll}
\hline Type & Vector & Source of proter & Coding sequence \\
\hline GUS expression & pTH207 & hsp70 from B. lactucae $(590 \mathrm{bp})$ & GUS $(1870 \mathrm{bp})$ \\
& pHAMT35G & ham34 from B. lactucae $(920 \mathrm{bp})$ & GUS $(1870 \mathrm{bp})$ \\
& pDHAMT35G & ham34 from B. lactucae $(400 \mathrm{bp})$ & GUS $(1870 \mathrm{bp})$ \\
& pPMA-HAM & act from P. megasperma $(1000 \mathrm{bp})$ & GUS $(1870 \mathrm{bp})$ \\
& pPAC-HAM & act A from P. infestans $(400 \mathrm{bp})$ & GUS $(1870 \mathrm{bp})$ \\
GUS antisense & pPUB-HAM & ubi3R from P. infestans $(757 \mathrm{bp})$ & GUS $(1870 \mathrm{bp})$ \\
& pHAMT35G-Rev & ham34 from B. lactucae $(920 \mathrm{bp})$ & anti-GUS $(1870 \mathrm{bp})$ \\
lacZ expression & pHAMT35GD-Rev & ham34 from B. lactucae $(920 \mathrm{bp})$ & anti-GUS $\left(5^{\prime}-550 \mathrm{bp}\right)$ \\
drug resistance & pHAMT35L & ham34 from B. lactucae $(920 \mathrm{bp})$ & lacZ $(3700 \mathrm{bp})$ \\
& pTH209 & hsp70 from B. lactucae $(590 \mathrm{bp})$ & nptII \\
\hline
\end{tabular}

"All vectors are based in pUC19 and contain transcription fusions with the indicated coding sequences, promoter, and a 550-bp transcriptional terminator fragment from the ham34 gene. Plasmids pHAMT35G, pPMA-HAM. pTH207, pTH209. and pTH210 have been described (Judelson et al., 400-bp promoter froment 1992) pPUB-HAM a PAC-HAM were constructed by excising the ham 34 promoter from pHAMT35G, and inserting either a 757-bp or 1991). 1991). The ubi3R fragment was excised from pPIN1 (C.M.J.P. and F. Govers, unpublished) by digestion with EcoRI, treatment with PolIk, and digestion with $\mathrm{NcoI}$ and inserted into pHAMT35G (which was digested with HindIII, treated with Pollk, and digested with NcoI). The act $A$ fragment was excised as a HindIII-NCOI fragment from pSTA48 (S.E.U. and J.R. Kinghorn. unpublished) and inserted into pHAMT35G digested with HindIII + NcoI. pDHAMT35G was constructed by deleting a 520 bp HindIII-PruII fragment from the 5 ' end of the ham 34 promoter in pHAMT35G. Plasmid pHAMT35L was constructed by removing the lac $Z$ gene from pSV $\beta$-Gal (Promega Corporation, Madison, WI, USA) by digestion with StuI + XbaI, blunt-ending the fragment with PolIk, and inserting it into the SmaI site of expression plasmid pHAMT35 (Judelson and Michelmore, 1991). Plasmids pHAMT35G-Rev and pHAMT35GD-Rev were constructed by inserting GUS sequences from pHAMT35G (excised as either the orion with $E c o R I+N c o I$, or as 550 bp of $5^{\prime} \mathrm{ORF}$ sequences by digestion with $\left.E c o \mathrm{RV}+N c o \mathrm{I}\right)$ in the antisense orientation into the SmaI site of pHAMT35, following treatment of the GUS fragments with PolIk.

TABLE II

Comparison of promoter activities in transient assays

\begin{tabular}{llll}
\hline Vector & Source of promoter fused to GUS & \multicolumn{2}{l}{ GUS specific activity $(\%)^{\mathrm{b}}$} \\
\hline pTH207 & hsp70 from B. lactucae & $819 \pm 66$ & $(100 \%)$ \\
pHAMT35G & ham34 from B. lactucae & $334 \pm 18$ & $(41 \%)$ \\
?PMA-HAM & act from P. megasperma & $273 \pm 32$ & $(33 \%)$ \\
pPAC-HAM & act A from P. infestans & $134 \pm 8$ & $(16 \%)$ \\
pPUB-HAM & ubi3R from P. infestans & $76 \pm 8$ & $(9.3 \%)$ \\
none & & $1 \pm 0$ & $(0.1 \%)$ \\
\hline
\end{tabular}

As described in Table I. Equimolar amounts to each vector (corresponding to $10 \mu \mathrm{g}$ pTH207) were introduced into $2 \times 10^{6}$ protoplasts of strain P1306 of $P$. infestans (provided by Michael Coffey, University of California, Riverside) as described (Judelson et al., 1991).

bAfter an overnight incubation of the protoplasts in rye media (Caten and Jinks, 1968) containing $1 \mathrm{M}$ mannitol, an extract was prepared from the protoplasts and assayed for GUS activity using 4-methylumbelliferyl- $\beta$-glucuronide as described (Judelson et al., 1991). Activity is expressed as pmol 4-methylumbelliferone released per min per mg protein at $37^{\circ} \mathrm{C}$. Values are averages of four independent transformations, \pm standard error. Indicated in parentheses are relative activities, compared to pTH207.

and the relative copy number of GUS sequences determined by dot-blot analysis (Fig. 2), although such an assay does not distinguish between intact and partial GUS genes. Southern hybridization analysis of nine other transformants containing pHAMT35G also failed to indicate a simple relationship between the relative number of intact GUS genes and their expression (not shown). Heterokaryosis was also considered as a cause of the low levels of GUS in some transformants. However, this was not supported by the observation that single-zoospore derivatives (zoospores are typically uninuclear) of two weakly-expressing transformants each expressed low levels of GUS activity similar to those observed in the original transformants (11 and 15 derivatives, respectively). Finally, the variation appeared determined at the level of transcription, as the levels of GUS mRNA detected in Northern blots of RNA from eight transformants expressing pPUB-HAM paralleled enzyme activities (not shown).

\section{(c) Stability of expression}

The expression of the GUS transgenes was usually mitotically stable, as measured by histochemical assays performed periodically during several months of vegetative 

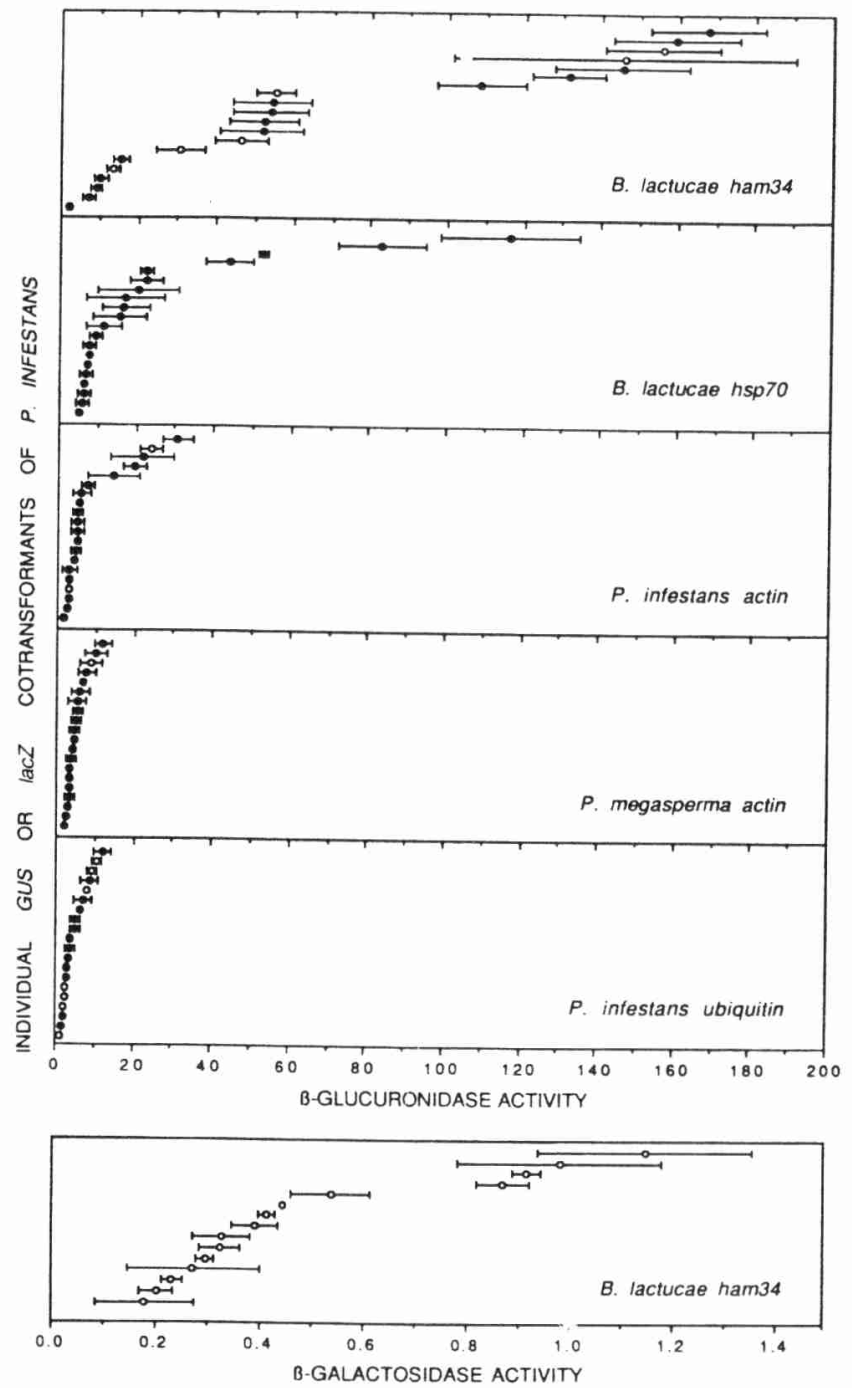

Fig. 1. Transgene expression in stable transformants. The specific activities (expressed as nmole $p$-nitrophenol released per min per mg protein at $37^{\circ} \mathrm{C}$ ) of GUS or $\beta \mathrm{Gal}$ in transformants of $P$. infestans were determined as described below. The promoter fused to GUS or lacZ is indicated in each panel. Individual transformants are represented along the vertical axis by each circle. Error bars represent range of values obtained from duplicate cultures, and are omitted when within the symbol. Methods: Protoplasts were transformed as described (Judelson et al., 1991) using either linear ( or supercoiled (O) plasmids. Cotransformation was performed using equimolar ratios of the nonselected plasmids (GUS or lacZ) and G418 ${ }^{\mathrm{R}}$ plasmid pTH209 (generally 15 to $30 \mu \mathrm{g}$ each). For experiments using the linear plasmids, the DNA was digested with EcoRI (cleaving 3' of the ham 34 terminator present in each vector) and purified by extraction with phenol and with chloroform, and precipitation with ethanol, prior to transformation. G418 ${ }^{R}$ colonies were assayed histochemically for GUS or $\beta G$ al activity approximately 2 weeks after DNA treatment. Samples were stained overnight at $37^{\circ} \mathrm{C}$ in $75 \mu \mathrm{l}$ of assay solutions for GUS $(0.05 \%$ 5-bromo-4chloro-3-indolyl- $\beta$-D-glucuronide $/ 10 \mathrm{mM} \quad \mathrm{Na}_{2} \mathrm{HPO}_{4}, \quad \mathrm{pH} 7.2 / 5 \mathrm{mM}$ $\mathrm{K}_{4} \mathrm{Fe}(\mathrm{CN})_{6} / 5 \mathrm{mM} \mathrm{K}_{3} \mathrm{Fe}(\mathrm{CN})_{6} / 0.1 \%$ Triton $\left.\mathrm{X}-100\right)$ or for $\beta \mathrm{Gal}(0.05 \%$ 5-bromo-4-chloro-3-indolyl- $\beta$-D-galactopyranoside/ $10 \mathrm{mM} \mathrm{Na}_{2} \mathrm{HPO}_{4}$ pH 7.2/50 mM NaCl/3.3 mM $\quad \mathrm{K}_{4} \mathrm{Fe}(\mathrm{CN})_{6} / 3.3 \mathrm{mM} \quad \mathrm{K}_{3} \mathrm{Fe}(\mathrm{CN})_{6} / 0.1 \%$ Triton $\mathrm{X}-100$ ). Specific activities were determined by colorimetric assay of extracts of vegetative mycelia. Care was taken to obtain cultures of equal development, due to the coenocytic growth habit of $P$. infestans. Mycelia were obtained by inoculating duplicate $5 \mathrm{ml}$ cultures of clarified rye broth (Caten and Jinks, 1968), in a $16 \mathrm{~mm} \times 100 \mathrm{~mm}$ plastic tube, culture. Transformants also continued to express the genes during growth in tomato as shown by histochemical staining and RNA hybridization. However, rare instances of a loss of GUS activity were noted involving each promoter. For example, of 57 pHAMT35G transformants that originally demonstrated GUS activity, 53 continued to display similar levels of GUS activity after three months in culture. 21 of the 53 transformants were grown for an additional three months, during which one lost GUS activity.

Five transformants in which the expression of GUS had been silenced were studied in more detail. DNA hybridization analysis indicated that two lacked GUS sequences, suggesting excision of the gene, sorting out of heterokaryons, or accidental mislabeling of cultures. The other three transformants retained normal pHAMT35G sequences, based on several diagnostic tests with restriction enzymes. No evidence was obtained to support hypermethylation of the silenced GUS genes, based on digests using the methylation-sensitive enzymes HpaII, which cuts within the GUS ORF, or PvuII, which digests within the promoter and terminator in pHAMT35G. To more definitively determine the integrity of the silenced GUS gene, pHAMT35G sequences were recovered from two silenced transformants by digestion of genomic DNA with HindIII, ligation, and transformation of E. coli; this was possible since tandem arrays of a few vector molecules frequently exist in transformants of $P$. infestans (Judelson et al., 1991). Ampicillin-resistan colonies were recovered that contained plasmids identica. in diagnostic restriction digest patterns to $\mathrm{pHAMT} 35 \mathrm{G}$. Two plasmids recovered from each of the two strains were reintroduced into P. infestans; all four behaved identically to the original pHAMT35G vector in terms of the frequency, intensity, and stability (over three months) of GUS expression. Silencing in at least these two transformants therefore did not appear to involve the mutation or excision of sequences required for GUS expression.

with $2 \mathrm{~mm}^{2}$ plugs of mycelia excised from the leading edge of an expanding colony. After 5-6 days at $19^{\circ} \mathrm{C}$ the colonies had filled the bottom half of the tubes, remaining submerged. Microscopic examinination of selected cultures confirmed that no sporulation occurred under these conditions. Occasional cultures growing much faster or slower than average were omitted from analysis. Mycelia were harvested by centrifugation and blended for $15 \mathrm{~s}$ at $4^{\circ} \mathrm{C}$ in $0.5 \mathrm{ml}$ GUS extraction buffer (Judelson and Michelmore, 1991). After clarification by centrifugation at $12000 \times g$ for $1 \mathrm{~min}$, the extracts were assayed for activity at $37^{\circ} \mathrm{C}$ using $2 \mathrm{mM} p$-nitrophenol- $\beta$-glucuronide in GUS extraction buffer, or $2 \mathrm{mM} p$-nitrophenol- $\beta$-galactoside in GUS extraction buffer plus $1 \mathrm{mM}$ $\mathrm{MgCl}_{2}$. Untransformed background activities of GUS and $\beta \mathrm{Gal}$ of $0.0 \pm 0$ and $0.08 \pm 0.01 \mathrm{u}$, respectively, were subtracted from the above data. 


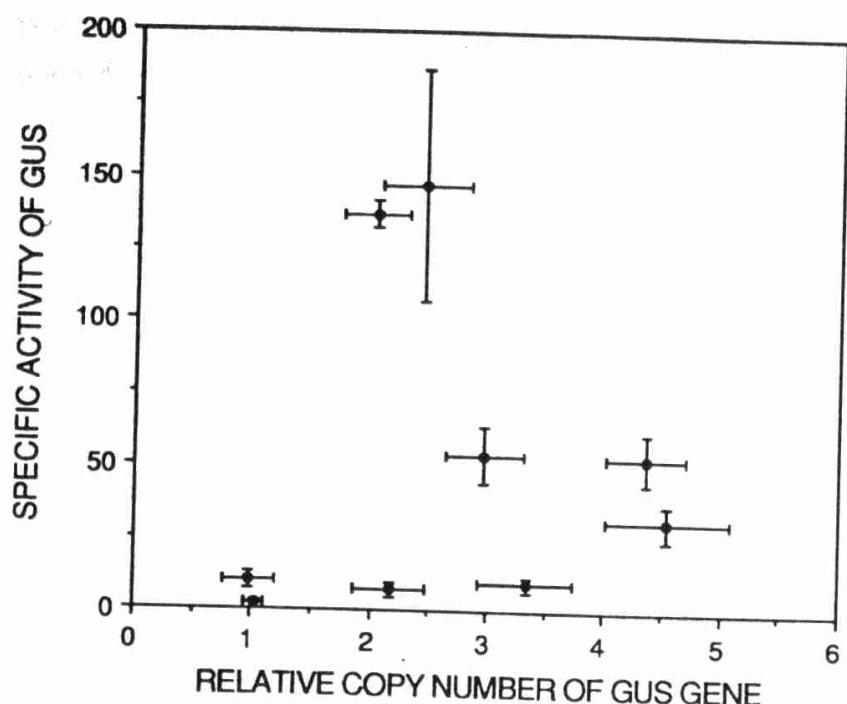

Fig. 2. Relationship between GUS activity and copy number. Relative copy numbers of the GUS gene were determined by dot-blot hybridization as described below; error bars represent standard accumulated error. GUS activities were determined as described in Fig. 1; error bars indicate the'range of GUS specific activities between duplicate cultures. Methods: DNA was extracted from pHAMT35G cotransformants as described (Raeder and Broda, 1985), and concentrations were determined by measurement of optical density. On nylon filters (Hybond $\mathrm{N}^{+}$, Amersham) placed in a 96-well vacuum manifold (Bio-Rad), $62.5 \mathrm{ng}, 250 \mathrm{ng}, 1 \mu \mathrm{g}$, and $2 \mu \mathrm{g}$ of DNA from transformants were spotted (in duplicate), along with a copy-number reconstruction containing pHAMT35G (linearized with HindIII) corresponding to $0,0.25,0.5,1$, $2,4,8,16,32$, and 64 copies perr haploid genome (in duplicate), relative to $250 \mathrm{ng}$ of genomic DNA and a genome size of $2.5 \times 10^{8}$ bp as determined by microfluorometry (Tooley and Therriën, 1987). Salmon DNA was added to each sample to a total of $2 \mu \mathrm{g}$ DNA. To apply the DNA to the membrane, the membrane was first wetted with $2 \times \mathrm{SSC}$, and then the DNA samples, in $10 \times \mathrm{SSC}$, were drawn through the filter using slow vacuum. The filters were rinsed witul $0.4 \mathrm{M} \mathrm{NaOH}$, removed from the manifold, washed for $5 \mathrm{~min} 0.4 \mathrm{M} \mathrm{NaOH}$, and washed for $2 \mathrm{~min}$ in $2 \times \mathrm{SSC}$. One filter was hybridized to a probe for the GUS ORF (1.87 kb NcoI-K pnI fragment of pHAMT35G). A duplicate filter was hybridized to a fragment of low-copy $P$. infestans DNA $(P I G-3)$. Hybridization was performed at $65^{\circ} \mathrm{C}$ in $0.5 \mathrm{M} \mathrm{Na}_{2} \mathrm{HPO}_{4}, \mathrm{pH} 7.2 / 7 \%$ SDS $/ 0.25 \mathrm{mM}$ $\mathrm{Na}_{2}$ EDTA using ${ }^{32} \mathrm{P}$-labelled probes prepared by the random primer method, and filters were washed twice for $15 \mathrm{~min}$ in $1 \times \mathrm{SSC} / 0.3 \%$ $\mathrm{SDS} / 0.1 \%$ sodium pyrophosphate at $65^{\circ} \mathrm{C}$ and $15 \mathrm{~min}$ in $0.1 \times \mathrm{SSC} / 0.3 \% \mathrm{SDS} / 0.1 \%$ sodium pyrophosphate at $65^{\circ} \mathrm{C}$. Films from autoradiography were analyzed using a computing laser densitometer and Imagequant software (Molecular Dynamics). Copy numbers were determined by comparing the unknowns to the internal pHAMT35G standard curve, using 4 points in the linear range. Adjustments were made for minor variation in DNA loading between samples using the filter hybridized to the $P I G-3$ genomic probe.

\section{(d) Inhibition of gene expression using antisense RNA}

The feasibility of using antisense RNA to inhibit the expression of genes in $P$. infestans was initially tested in transient assays, by treating protoplasts with varying ratios of sense and antisense GUS constructs (Fig. 3). A full-length antisense construct (pHAMT35G-Rev) and one containing only $550 \mathrm{nt}$ of $5^{\prime}$ coding sequences (pHAMT35GD-Rev) were both effective at reducing

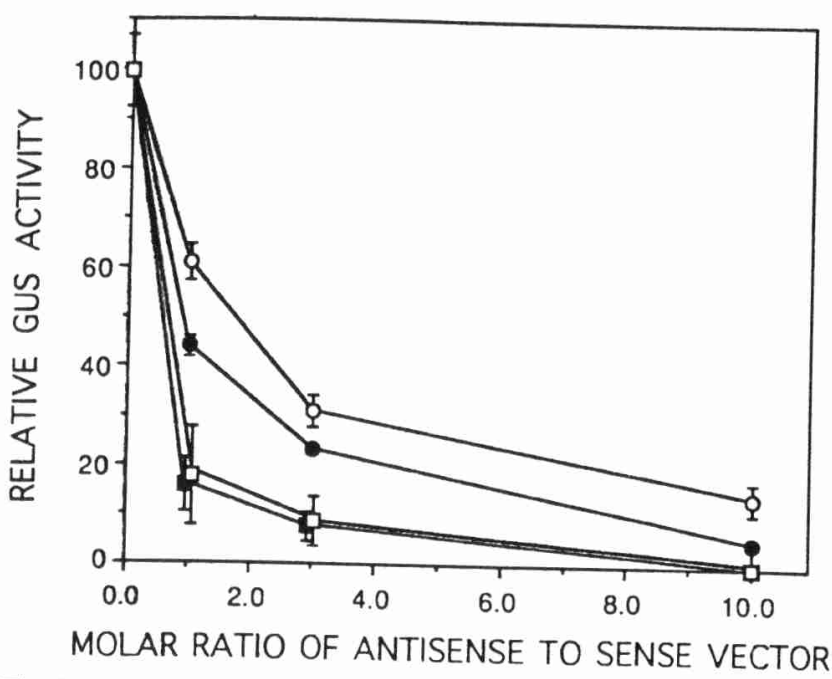

Fig. 3. Antisense inhibition of GUS in protoplasts. Transient assays were performed in protoplasts of $P$. infestans as described in the legend of Table II, using varying ratios of sense and antisense GUS expression plasmids. Values are expressed as per cent expression of GUS, relative to samples treated with GUS sense plasmids alone (average GUS specific activities were $68 \pm 3 \mathrm{u}$ for pHAMT35G, and $18 \pm 1 \mathrm{u}$ for pPUB -HAM); the average of four determinations is presented. Error bars indicate the range of values, and are omitted when within the symbol. Each treatment used $5 \mu \mathrm{g}$ of pPUB-HAM or pHAMT35G, plus varying amounts of the antisense plasmids as indicated. (1), pHAMT35G and pHAMT35G-Rev; (O) pHAMT35G and pHAMT35GD-Rev; (a) pPUB-HAM and pHAMT35G-Rev; ( $\square$ ) pPUB-HAM and pHAMT35GD-Rev.

GUS activity derived from sense vectors containing the ham34 promoter (pHAMT35G) or ubiquitin promoter (pPUB-HAM). Increasing amounts of the antisense construct resulted in increased inhibitıon. Less antisense vector was required to reduce the expression of GUS from the ubiquitin promoter, which is weaker than the ham 34 promoter.

The full- and partial-length antisense constructs were also tested in stable transformants, by retransformation of strains $\mathrm{J} 613$ and T513. J613 was a GUS ${ }^{+}, \mathrm{G} 418^{\mathrm{R}}$ transformant constructed using pTH209 and pPUB-HAM (GUS specific activity of $11.3 \pm 1.6 \mathrm{u}$ ). T513 was a GUS ${ }^{+}$, $\mathrm{Hy}^{\mathrm{R}}$ transformant obtained with pHAMT35G and pTH210 (GUS specific activity of $90 \pm 16 \mathrm{u}$ ). The antisense constructs were introduced into $\mathrm{J} 613$ and $\mathrm{T} 513$ by cotransformation with pTH210 or pTH209, respectively.

Among derivatives of J613, six of 34 colonies resulting from cotransformation with pHAMT35GD-Rev and four of 20 resulting from cotransformation with pHAMT35GRev showed little or no GUS staining in a histochemical assay. Of 18 colonies randomly selected from the $54 \mathrm{Hy}^{\mathrm{R}}$ transformants, 12 were shown by PCR to contain antisense GUS vectors. Therefore, of the 54 colonies assayed for GUS, about $67 \%$ would have been expected to contain the antisense gene. Apparently, only a fraction of these expressed levels of antisense RNA adequate to in- 
hibit the acce'mulation of GUS. In a control treatment executed in parallel, each of 30 colonies recovered by retransformation of J613 using pTH210 alone expressed levels of GUS activity similar to J613.

Attempts to inhibit GUS expression in T513, where GUS was expressed using the strong ham 34 promoter, were less successful. Of 47 colonies recovered from the retransformation of T513, only one (treated with pHAMT35G-Rev) showed an obvious reduction of GUS activity based on histochemical staining. Each of 24 control transformants (retransformed with pTH209 only) continued to express GUS.

Several data indicated that inhibition of GUS expression in the GUS-negative derivatives of J613 was the authentic consequence of antisense inhibition, rather than spontaneous silencing of the GUS transgene. Hybridization analysis of RNA from transformants Q22 and Q25 (derivatives of J613 containing pHAMT35GDRev) detected GUS mRNA in addition to a much higher level of antisense RNA (Fig. 4). The level of GUS mRNA was much lower than that observed in J613 and Q17, a retransformant of J613 obtained using pTH210 but not an antisense vector. The reduction in sense mRNA levels is similar to that observed in other species (Rothstein et al., 1987), but not as extreme as in some (Robert et al., 1989). Degradation of sense-antisense complexes may account for this reduction. Quantitative assays also revealed low but detectable levels of GUS activity in Q22 and Q25 (0.20 and (.22 u), above the negligible levels in wild-type $P$. infestans, indicating that $98 \%$ inhibition had been achieved.

\section{(e) Conclusions}

(1) DNA fragments from the upstream regions of five oomycete genes were shown to have promoter activity in protoplasts and in stable transformants of $P$. infestans. The strengths of the promoter fragments varied substantially, indicating opportunities for expressing genes to high or low levels in future experiments. Two sequences shown here and previously (Judelson and Michelmore, 1991) to be active in P. infestans came from a related oomycete, B. lactucae. All of these promoters may therefore be useful throughout the oomycetes.

(2) Significant variability was observed in the quantitative expression of foreign genes in P. infestans, which was not simply correlated with copy number. Similar variation resulting from chromosomal position effects has been widely reported in plants and animals (Al-Shawi et al., 1990; Dean et al., 1988; Spradling and Rubin, 1983). The influence of position effects on transgene expression in higher fungi has been reported, but on average appears less extreme than observed for plants, animals, and P. infestans (Bunkers, 1991; Kinsey and Rambosek, 1984;
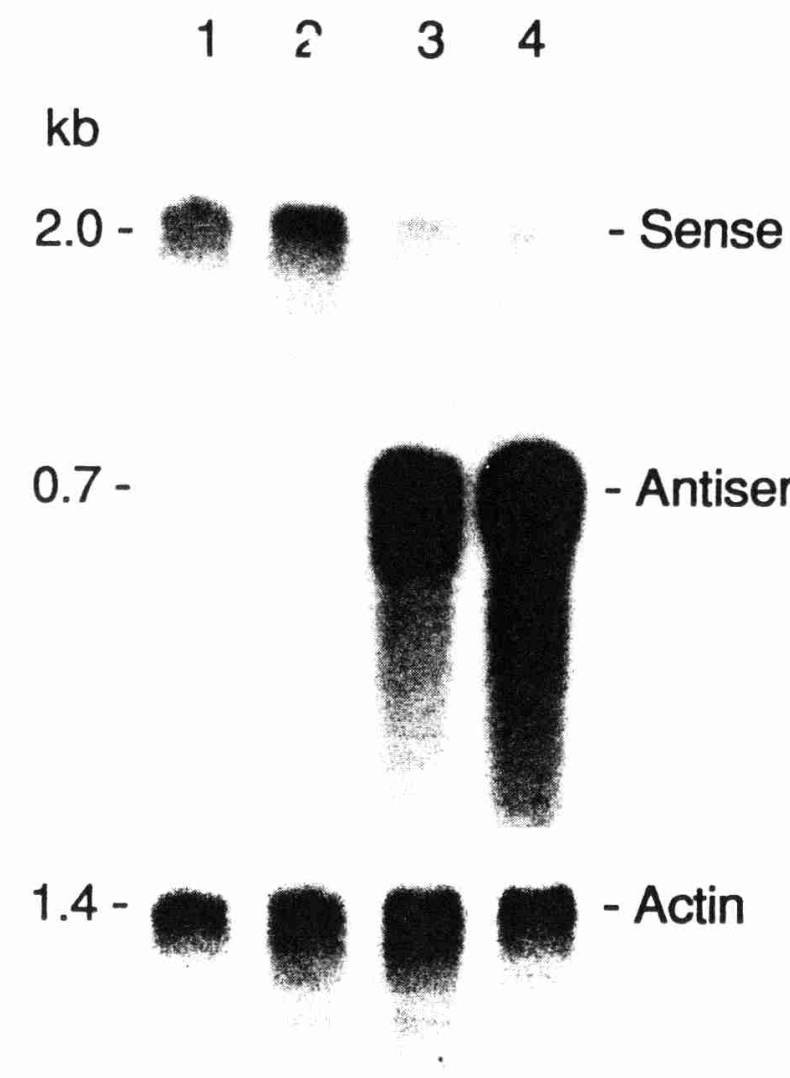

Fig. 4. Antisense inhibition of GUS expression in stable transformants. RNA was resolved on $1.2 \%$ agarose- $2.2 \mathrm{M}$ formaldehyde gels as described (Judelson et al., 1991), transferred to nylon membranes, and hybridized to ${ }^{32} \mathrm{P}$-labelled probes as in Fig. 2. Lane 1, $2 \mu \mathrm{g}$ RNA from J613; lane 2, $2 \mu \mathrm{g}$ RNA from Q17 (J613 retransformed with pTH210 only); lanes 3 and 4, $2 \mu$ g RNA 1.om Q22 and Q25 (J613 retransformed with pTH210 and pHAMT35Gi - Rev). The filter was hybridized to a probe for the $5^{\prime}$ end of the GUS gene (a 550-bp NcoI-EcoRV fragment of pHAMT35G) (top panel), and then stripped and rehybridized with a probe for actin (750-bp HindIII fragment from act A; Unkles et al., 1991). Band sizes (indicated in the left margin) were determined using a RNA ladder (BRL) as a size standard.

Van Gorcom et al., 1985). Position effects in P. infestans may reflect the more complex genomes with extensive repeat sequences in the Phytophthora genus, compared to other fungi (Mao and Tyler, 1991).

(3) The expression of transgenes was generally stable, but occasionally their expression ceased. Silencing of the transgene was not associated with a discernible mutation in the vector, indicating that caution must be exercised when using transformation to evaluate the function of genes. Instability of transforming sequences has been described in higher fungi but is commonly associated with the excision of transforming sequences (Tooley et al., 1992; Keller et al., 1991).

(4) Antisense RNA was effective in inhibiting the accumulation of gene products such as GUS, especially when a strong promoter (i.e., from the ham 34 gene) could be used to repress the expression of a gene with a weaker promoter (i.e., from the $u b i 3 R$ gene). Demonstration of 
the antisense technique is particularly meaningful since gene disruption strategies, commonly performed in some higher fungi, are not yet feasible in $P$. infestans since homologous recombination between plasmid and genumic sequences has not been observed. Also, since oomycetes are diploid, two rounds of disruption would be required to silence a native gene.

\section{ACKNOWLEDGEMENTS}

This work was supported by USDA grant 91-373036694 to H.S.J., NSF grant BIR-8920216 to the Center for Engineering Plants for Resistance Against Pathogens, and AFRC grant LRG-85 to S.E.U.

\section{REFERENCES}

Ainley, W.M. and Key, J.L.: Development of a heat shock inducible expression cassette for plants- characterization of parameters for its use in transient expression assays. Plant Mol. Biol. 14 (1990) 949-967.

Al-Shawi, R., Kinnaird, J., Burke, J. and Bishop, J.O.: Expression of a foreign gene in a line of transgenic mice is modulated by a chromosomal position effect. Mol. Cell. Biol. 10 (1990) 1192-1198.

Bartnicki-Garcia, S.: Cell wall chemistry, morphogenesis, and taxonomy of fungi. Annu. Rev. Microbiol. 22 (1968) 87-108.

Bunkers, G.J.: Expression of the Escherichia coli $\beta$-glucuronidase gene in Pseudocercosporella herpotrichoides. Appl. Environ. Micro. 57 (1991) 2896-2900.

Caten, C.E. and Jinks J.L.: Spontaneous variability of single isolates of Phytophthora infestans, I. Cultural variation. Can. J. Bot. 46 (1968) 329-348.

Dean, C., Jones, J., Favreau, M., Dunsmuir, P. and Bedbrook, J.: Influence of flanking sequences on variability in expression levels of an introduced gene in transgenic tobacco plants. Nucleic Acids Res. 16 (1988) 9267-9283.

Dudler, R.: The single copy actin gene of Phytophthora megasperma encodes a protein considerably diverged from any other known actin. Plant Mol. Biol. 14 (1990) 415-422.

Förster, H., Coffey, M.D., Elwood, M. and Sogin, M.L.: Sequence analysis of the small subunit ribosomal RNAs of three zoosporic fungi and implications for fungal evolution. Mycologia 82 (1990) 306-312.

Johnson, P.F. and McKnight, S.L.: Eukaryotic transcriptional regulatory proteins. Annu. Rev. Biochem. 58 (1989) 799-839.

Judelson, H.S., Coffey, M.D., Arredondo, F.R. and Tyler, B.M.: Transformation of the soybean pathogen Phytophthora megasperma f. sp. glycinea occurs by DNA integration into single or multiple chromosomes. Curr. Genet. 23 (1993) 211-218.
Judelson, H.S. and Michelmore, R.W.: Transient expression of foreign genes in the oomycete Phytophthora infestans using Bremia lactucae regulatory sequences. Curr. Genet. 19 (1991) 453-459.

Judelson, H.S. and Michelmore, R.W.: Highly abundant and stagespecific mRNAs in the obligate pathogen Bremia lactucae. Mol. Plant-Microbe Interact. 3 (1990) 225-232.

Judelson, H.S. and Michelmore, R.W.: Structure and expression of a gene encoding heat-shock protein $\mathrm{Hsp} 70$ from the oomycete fungus Bremia lactucae. Gene 79 (1989) 207-217.

Judelson, H.S., Tyler, B.M. and Michelmore, R.W.: Regulatory sequences for expressing genes in oomycete fungi. Mol. Gen. Genet. 234 (1992) 138-146.

Judelson, H.S., Tyler, B.M. and Michelmore, R.W.: Transformation of the oomycete pathogen, Phytophthora infestans. Mol. Plant-Microbe Interact. 4 (1991) 602-607.

Keller, N.P., Bergstrom, G.C. and Yoder, O.C.: Mitotic stability of transforming DNA is determined by its chromosomal configuration in the fungus Cochliobolus heterostrophus. Curr. Genet. 19 (1991) 227-233.

Kinsey. J.A. and Rambosek, J.A.: Transformation of Neurospora crassa with the cloned am (glutamate dehydrogenase) gene. Mol. Cell. Biol. 4 (1984) 117-122.

Mao, Y. and Tyler, B.M.: Genome organization of Phytophthora megasperma f. sp. glycinea. Exp. Mycol. 15 (1991) 283-291.

Pieterse, C.M.J., Risseeuw, E.P. and Davidse, L.C.: An in planta induced gene of Phytophthora infestans codes for ubiquitin. Plant Mol. Biol. 17 (1991) 799-811.

Raeder, U. and Broda, P.: Rapid preparation of DNA from filamentous fungi. Lett. Appl. Microbiol. 1 (1985) 17-20.

Robert, L.S., Donaldson, P.A., Ladaique, C., Altosaar, I., Arnison, P.G. and Fabijanski, S.F.: Antisense RNA inhibition of $\beta$-glucuronidase expression in transgenic tobacco plants. Plant Mol. Biol. 13 (1989) 399-409.

Rothstein, S.J., DiMaio, J., Strand, M. and Rice, D.: Stable and heritable inhibition of the expression of nopaline synthase in tobacco expressing antisense RNA. Proc. Natl. Acad. Sci. USA 84 (1987) 8439-8443.

Spradling, A.C. and Rubin G.M.: The effect of chromosomal position on the expression of the Drosophila xanthine dehydrogenase gene. Cell 34 (1983) 47-57.

Tooley, P.W., Leung, H. and Leong, S.A.: Meiotic and mitotic stability of transforming DNA in the phytopathogenic fungus Magnaporthe grisea. Curr. Genet. 21 (1992) 55-60.

Tooley, P.W. and Therriën, C.D.: Cytophotometric determinations of the nuclear DNA content of 23 Mexican and 18 non-Mexican isolates of Phytophthora infestans. Exp. Mycol. 11 (1987) 19-26.

Unkles, S.E., Moon, R.P., Hawkins, A.R., Duncan, J.M. and Kinghorn, J.R.: Actin in the oomycetous fungus Phytophthora infestans is the product of several genes. Gene 100 (1991) 105-112.

Van Gorcom, R.F.N., Pouwels, P.H., Goosen, T., Visser, J., Van den Broek, H.W.J., Hamer, J.E., Timberlake, W.E. and Van den Hondel, C.A.M.J.J.: Expression of an Escherichia coli $\beta$-galactosidase fusion gene in Aspergillus nidulans. Gene 40 (1985) 99-106.

Warner, S.A., Sovocool, G.W. and Domnas, A.J.: Sterols of selected species of oomycetes and hypochytridiomycetes. Mycologia 75 (1983) 285-291 